\title{
Development of a novel microbicide for control of foodborne pathogens
}

\section{Introduction}

The efficacy of many chlorine-based sanitizers currently used in food processing facilities is reduced when organic matter is present, whereby their usefulness as an antimicrobial is mitigated. Effective sanitizers that are effective, practical, cost-efficient and environmentally-friendly are needed to control food borne pathogens and their biofilms in food processing facilities. To gain all these purposes and at the same time to ensure the quality of treated food unchanged, various organic acids and detergents were evaluated individually and in combination for their bactericidal activity. We revealed that either organic acids or detergents did not show significant bactericidal effect when used individually. However, a combination just including two chemicals, levulinic acid and sodium dodecyl sulfate (SDS) can inactivate all bacteria as tested. Results revealed that a solution with $0.5 \%$ levulinic acid and $0.05 \%$ SDS provided a ca. $7 \log \mathrm{CFU} / \mathrm{ml}$ reduction of E. coli $\mathrm{O} 157: \mathrm{H} 7$, S. Enteritidis, and S. Typhimurium DT104 within $1 \mathrm{~min}$ (processing time). Its effect as a rinse solution to remove E. coli $\mathrm{O} 157: \mathrm{H} 7$ and Salmonella was confirmed with romaine lettuce and poultry skin. ${ }^{1}$ The advantage of levulinic acid over other organic acids is its characteristics; including it does not produce corrosion, its safety to human, and it can keep the quality of treated produce.

The number of sprout-related outbreaks has an increased tendency. The method to kill all the pathogens (human and plant) in seeds and to guarantee their germination rate is not interfered is demanded. Studies were done to determine the best concentration and exposure time for treatment of the alfalfa seeds with levulinic acid plus SDS to inactivate E. coli $\mathrm{O} 157: \mathrm{H} 7$ and Salmonella and not adversely affect seed germination. Alfalfa seeds contaminated with E. coli $\mathrm{O} 157: \mathrm{H} 7$ were subsequently dried at $21^{\circ} \mathrm{C}$ in a laminar flow hood for up to $72 \mathrm{~h}$. Results demonstrated that a 5 -min treatment at $21^{\circ} \mathrm{C}$ of alfalfa seeds contaminated with 108 E. coli O157:H7 or S. Typhimurium DT 104 of a solution containing $0.5 \%$ levulinic acid plus $0.05 \%$ SDS reduced E. coli $\mathrm{O} 157: \mathrm{H} 7$ and S. Typhimurium DT 104 populations by 5.6 and $6.4 \log 10 \mathrm{CFU} / \mathrm{g}$, respectively. Treatment of seeds contaminated with 104 E. coli $\mathrm{O} 157: \mathrm{H} 7$ or S. Typhimurium CFU in a glass beaker and then in a stomacher bag with $0.5 \%$ levulinic acid plus $0.05 \%$ SDS at $21^{\circ} \mathrm{C}$ for a total of $20 \mathrm{~min}$ reduced E. coli $\mathrm{O} 157: \mathrm{H} 7$ or S. Typhimurium DT 104 in all samples $(25 \mathrm{~g})$ to undetectable levels by a direct plating method $(<0.7 \log 10 \mathrm{CFU} / \mathrm{g})$, but 8 of 10 samples were detectable by selective enrichment culture. Germination rates of alfalfa seeds treated with $0.5 \%$ levulinic acid plus $0.05 \%$ SDS for up to $1 \mathrm{~h}$ at $21^{\circ} \mathrm{C}$ were compared with a treatment of $20 \mathrm{mg}$ calcium hypochlorite $/ \mathrm{ml}$ and tap water only treatment. Results revealed that treatment with $0.5 \%$ levulinic acid plus $0.05 \% \mathrm{SDS}$ for $1 \mathrm{~h}$ at $21^{\circ} \mathrm{C}$ did not adversely affect alfalfa seed germination compared to the control treatment with tap water, whereas treatment with $20 \mathrm{mg}$ calcium hypochlorite for $1 \mathrm{~h}$ substantially reduced germination. ${ }^{2}$ Currently their efficacy to kill all the plant pathogens is in progress. Many food borne outbreaks were closely linked with the biofilm formation in food processing facilities. The antimicrobial efficacy of this sanitizer applied either as a liquid or as foam (under pressure) demonstrated excellent bio film removal specificity when compared with other sanitizers. ${ }^{3,4}$ Contaminated

\author{
Volume I Issue I - 2015
}

Tong Zhao

Center for Food Safety, University of Georgia, Georgia

Correspondence: Tong Zhao, Center for Food Safety, University of Georgia, Georgia 30223,Email tongzhao@uga.edu

Received: April 2, 2015 | Published: May 12, 2015

slicer surfaces sprayed with this sanitizer as a foam $(45-55 \mathrm{psi})$ reduced within $1 \mathrm{~min} 6.0$ to $8.0 \log \mathrm{CFU}$ of the three pathogens per blade. Results revealed that pathogenic transfer rate between slicers and foods depend on food contact locations on slicers, the composition of food, and the nature of pathogens. Also, Levulinic-based sanitizer applied as foam can be used as a potential method to remove microbial contamination on the surface of deli slicers. ${ }^{5}$

The safety of levulinic acid were tested for humans and thoroughly evaluated by world health organization because its addition in tobacco and it has GRAS status for direct addition to food as a flavoring substance or adjunct (FDA 2008, 21 CFR, 172.515). We confirmed its property by soaking whole Romaine lettuce in $0.5 \%$ levulinic acid plus $0.05 \%$ SDS for either 15 or $30 \mathrm{~min}$, then rinsing the lettuce with water three times and storing the treated lettuce and lettuce rinsed with water only (control) at $5^{\circ} \mathrm{C}$ for up to 14 days to observe the color change. There were no visual differences between the lettuce treated with $0.5 \%$ levulinic acid plus $0.05 \%$ SDS for 15 or $30 \mathrm{~min}$ and the lettuce rinsed with water only. Sodium dodecyl sulfate has GRAS status for multipurpose additives (FDA 2007, 21 CFR, 172.822). Its safety has been demonstrated by dental industry. Since our first publication with development of this sanitizer, many researchers have validated its application in different field. Dental doctors use it as a mouth rinse to remove dental biofilms in vitro and in vivo. Their studies revealed its efficacy to remove dental biofilm is significantly better than the commonly used Listerine. ${ }^{6}$ Its efficacy as virocide to inactivate nor virus and influenza A virus in various foods has been validated by different researchers ${ }^{7,8}$ at present its application in preharvested produce for inactivation of food borne pathogens and plant pathogens has been documented.

\section{Conclusion}

An alternative to chlorine-based sanitizer is developed and validated for its efficacy in various applications at food processing facilities for reduction of food borne pathogens and for their biofilm removal. ${ }^{9,10}$ At present a patent for its application was issued by U.S. patent office and licensed by Health Pro Inc. Its efficacy has been validated in various applications.

\section{Acknowledgements}

None. 


\section{Conflict of interest}

The author declares no conflict of interest.

\section{References}

1. Zhao T, Zhao P, Doyle MP. Inactivation of Salmonella and Escherichia coli O157:H7 on lettuce and poultry skin by combination of levulinic acid and sodium dodecyl sulfate. J Food Prot. 2009;72 (5):928-936.

2. Zhao T, Zhao P, Doyle MP. Inactivation of Escherichia coli O157:H7 and Salmonella Typhimurium DT 104 on Alfalfa seeds by levulinic acid and sodium dodecyl sulfate. J Food Prot. 2010;73(11):2010-2017.

3. Chen D, Zhao T, Doyle MP. Single- and mixed-species biofilm formation by Escherichia coli O157:H7 and Salmonella, and their sensitivity to levulinic acid plus sodium dodecyl sulfate. Food Control. 2015;57:48-53.

4. Chen D, Zhao T, Doyle MP. Control of pathogens in biofilms on the surface of stainless steel by levulinic acid plus sodium dodecyl sulfate. Int J Food Microbiol. 2015;207:1-7.

5. Chen D, Zhao T, Doyle MP. Transfer of food borne pathogens during mechanical slicing and their inactivation by levulinic acid-based sanitizer on slicers. Food Microbiol. 2014;38:263-269.
6. Wang BY, Hong J, Ciancio SG, et al. A novel formulation effective in killing oral biofilm bacteria. J Int Acad Periodontol. 2012;14(3):56-61.

7. Aydin A, Cannon JL, Zhao T, et al. Efficacy of a levulinic acid plus sodium dodecyl sulfate (SDS)-based sanitizer on inactivation of influenza A virus on eggshells. Food Environ Virol. 2013;5:215-219.

8. Cannon JL, Aydin A, Mann AN, et al. Efficacy of a levulinic acid plus sodium dodecyl sulfate-based sanitizer on inactivation of human norovirus surrogates. J Food Prot. 2012;75(8):1532-1535.

9. Zhao T, Zhao P, Cannon JL, et al. Inactivation of Salmonella in biofilms, and on chicken cages and preharvest poultry by levulinic acid and sodium dodecyl sulfate. J Food Prot. 2011;74 (12):2024-2030.

10. Zhao T, Zhao P, Chen D, et al. Reduction of Shiga toxin-producing Escherichia coli and Salmonella Typhimurium on beef trim by lactic acid, levulinic acid, and sodium dodecyl sulfate treatment. J Food Prot. 2014;77(4):528-537. 